\title{
The Impact of Flipped Project-Based Learning on Self-Regulation in Higher Education
}

\author{
https://doi.org/10.3991/ijet.v15i17.14135 \\ Mohamed Yassine Zarouk $(\bowtie)$ \\ University of Porto, Portugal \\ Abdelmalek Essaadi University, Tetouan, Morocco \\ medyassinezarouk@gmail. com \\ Eugénio Olivera \\ University of Porto, Portugal \\ Paula Peres \\ Polytechnic Institute of Porto, Portugal \\ Mohamed Khaldi \\ Abdelmalek Essaadi University, Tetouan, Morocco
}

\begin{abstract}
The combination of project-based learning (PBL) and flipped classroom methods offer learners the opportunity to go beyond content acquisition to develop further lifelong learning skills. To this end, we proposed a flipped project-based learning approach (SRPBL) that foster self-regulated learning (SRL) strategies in higher education. In this study, the authors examined the impact and effectiveness of the proposed approach on various facets of students' SRL, including motivational beliefs, self-regulation strategies, and collaborative strategies. A quasi-experimental research design that compared pretest and posttest measures for 83 students distributed into four groups enrolled in different curricular courses across different disciplines: economics, tourism, translation, and science of information. These courses took place under the guidance and assistance of five facilitators, providing appropriate scaffolding and resources for students. Overall, the results revealed that the flipped PBL approach has significantly enhanced students' SRL skills. It was found that the approach improved the students' self-regulation performance among different groups above their disciplines and levels. The findings indicated that students who actively engaged within flipped PBL activities demonstrated increases in cognitive and metacognitive functioning both individually and collaboratively. Participants also claimed that the approach was useful and effective. Furthermore, qualitative data revealed that the pedagogical role of facilitators and the course designing are determinant factors for the effectiveness of these studentcentered learning environments. This study contributes to an advance in the understanding of how the development of self-regulated learning strategies can be integrated into a flipped project-based learning environment in higher education.
\end{abstract}


Keywords-Self-Regulated Learning (SRL), Project-Based Learning (PBL), Flipped Classroom, Student-Centered Learning Environment, Higher Education.

\section{Introduction}

The rapid growth of technology has sparked a revolution in all life's aspects, and the future is even more uncertain. Today's labor market requires students to possess a wide range of skills, often referred to as 21 st century skills, beyond mastering the basic skills of their specific disciplines. Meanwhile, the world runs on projects, managing them, and solving complex problems became essential lifelong skills [1]. That required a drastic paradigm-changing in education. Nevertheless, most education systems have not developed pedagogical materials or teaching and learning methods that best prepare students for their present and future world [2]. As a result, the gap between what students are being taught and the skills needed for success continues to widen. On the contrary, Student-centered learning activities usually involve higher thinking skills [3], which can be seen as interdisciplinary learning projects. Considering that self-regulated learning (SRL) abilities are vital for students' lifelong learning [4], there is a growing demand to develop self-regulated learning strategies by building integrated learning environments in which students can solve complex problems. A student-centered learning environment (SCLE) makes SRL processes visible to learners, educators, and researchers for better pedagogical design and practice [5].

Throughout the exploration and resolution of ill-defined learning activities, SRL processes get at stake into mutual interactions: metacognitive, cognitive, motivational, and social [6]. This is especially true for project-based learning when combined with the reverse classroom method for an effective SCLE. Learners can develop their SRL skills while working on PBL activities as part of the curriculum. However, how learners can develop their self-regulatory strategies within student-centered learning environments has not been fully explored. Particularly, few studies provide empirical evidence concerning the effectiveness of PBL on students' self-regulation performance [7]. Thus, a flipped project-based learning approach (SRPBL) was implemented within an SCLE to support self-regulatory processes. The propose of this study is to examine the impact and effectiveness of a proposed approach on students' selfregulated learning strategies (motivational beliefs, self-regulation strategies, and collaborative strategies).

\subsection{Project-based learning fostering self-regulated learning}

Over the last decades, the paradigm of education has shifted gradually from a teacher-centered to a student-centered approach [8]. That has placed learners in the center of the learning process, by increasing awareness and control over their own learning. The role of educators is therefore seen as requiring the explicit teaching of autonomy, self-regulation, and the notion of lifelong learning at the heart of their instructional activities [9]. 
Self-regulated learning is defined as an active and constructive process in which learners participate metacognitively, motivationally, and behaviorally in their learning process while being guided by their goals and the contextual characteristics of their environments [10, 11]. SRL is a good predictor of academic achievement and has a great influence on the development of lifelong learning skills [12]. Fortunately, there is notable agreement on the teachability of SRL, but there has not yet been consensus on how it can be operationalized effectively [13, 14]. Studies have emphasized on situated learning approaches in which SRL is conceptualized as a set of dynamic context-dependent activities, whereby both learner, teacher, and environment characteristics can influence the SRL process [15].

From a social cognitive perspective, researchers also have suggested that problembased learning and generally project-based learning (PBL), as suitable approaches supporting the development of self-regulated learning [16]. PBL is a student-centered method that promotes active learning by allowing students to learn collaboratively for an extended period of time to investigate meaningful problems, brainstorm solutions, manage time and resources, assess and communicate results [17]. Projects as openended tasks that can stimulate students' interest and motivation, and offer opportunities for decision making, goal setting, strategic planning, self- monitoring, and performance reflection [18]. These features and the student-centered nature of PBL help to create effective learning environments that foster self-regulated learning. The whole process takes place under the guidance and assistance of a facilitator (teacher). The role of the facilitator is to provide appropriate scaffolding and resources for students, stimulate discussion, provide relevant content when needed, monitor team progress and individual contributions, and evaluate the work results [12]. Namely, instructional facilitation is focused on the metacognitive process [8].

Flipped learning methods may considerably contribute to saving more time for the metacognitive process and the development of higher-level thinking skills by reducing the cognitive load PBL activities [19]. It changes the student learning behavior from passive to active learning, and then improve learning outcomes [20], [21]. Students in flipped learning activities seem to adopt a positive attitude toward their, peers and shown better performance [22]. The combination of project-based learning and flipped classroom methods offer the opportunity to go beyond content acquisition to develop further lifelong learning skills and competencies [23]. Flipped PBL Environments contribute considerably to save more time both for students and facilitators, for interaction, the metacognitive process, and the development of higher-level thinking skills by reducing the cognitive load PBL activities [24]. Besides, the flipped classroom method as an emerging form of blended learning is already a trend in education and is expected to become the new normal in higher education [25]

\subsection{Related works and research questions}

Several studies have recently examined the effectiveness of student-centered learning environments based on PBL and blended learning approaches, on the development of self-regulation strategies. These studies explored theoretical frameworks and practical methodologies on how student regulated their learning. [26] Researchers stressed 
that a flexible and student-centered learning environment, used as a complement to the "Research Project" course, increased student interest, supported the development of various skills, and contributes to the overall improvement of the teaching and learning process. In this sense, [18] T.-Y. Mou studied students' experiences in a PBL environment for a computer science course (3D design). They found in their study that the adoption of methods complementary to the project-based learning approach promotes students' confidence, practical ability, interest in the subject matter, and, above all, their self-regulated learning attitude. [8] S. Sungur and C. Tekkaya also studied the effect of PBL on SRL in biology classes, they suggested that teachers adopt the PBL approach to improve student achievement by going beyond teaching content to teaching students how to learn. They found that PBL students strongly promoted different facets of self-regulation: motivational beliefs, metacognitive strategies, regulation persistence, and peer learning. [27] S. Kardipah and B. Wibawa conducted a study to explore the effectiveness of problem-based learning in a blended learning environment on student performance and motivation. Flipped PBL had a significant effect on student performance (computer skills). In addition, the approach also motivated students to become more engaged, guided them, and freed up classroom time. [23], [28] F. Paraskeva and al. have developed a conceptual framework based on PBL and SRL within a blended learning environment for "research methodology" courses in undergraduate schools. Analysis of the results reveals that the proposed approach fostered students' motivation, learning strategies, collaborative skills, and helped them better understand and apply the principles of the PBL method as they acquired the concepts of research methodology.

These related studies provide valuable insights and practical recommendations on how the adoption of student-centered approaches such as flipped learning and PBL might support students' SRL skills effectively. However, there are still limited studies that provide empirical evidence about the effectiveness and the cohesion of Flipped PBL environments on different facets of students' self-regulation in higher education [8], [29]. Moreover, we noticed that most of the studies based their educational frameworks on generic models of SRL and PBL and they do not offer contextual and integrated theoretical frameworks for the operationalization of such approaches and methods. Also, most of the studies based on their result generalizations such specific topics and a very homogenous group of students of the same level and disciplines. That led us to the present study, in which we examined the impact and the effectiveness of a proposed approach for flipped PBL on different facets of students' selfregulated learning: motivational beliefs, self-regulation strategies, and collaborative strategies. To this end, we implemented multiple case studies for different topics in different disciplines (Economics, Science of information, Tourism, and Translation), and students from different levels. Accordingly, we posed the following research questions:

1. Does the flipped project-based learning approach foster students' self-regulated learning skills: motivational beliefs, self-regulation strategies, and collaborative strategies in higher education? 
2. Does the flipped project-based learning approach foster students' self-regulated learning skills between groups across different disciplines and levels?

The flowing sections describe the proposed approach and methodology that contribute to addressing the posed research questions.

\section{Methods}

The study aims to examine the impact and effectiveness of a flipped project-based learning approach on students' self-regulated learning strategies in higher education. It serves therefore for two purposes. First, explanatory because it explains a possible cause-effect relationship, and then for refining and improving the proposed approach (SRPBL). It is a quasi-experiment study following a pretest-posttest design. We adopted a mixed methodology that combines quantitative and qualitative instruments for the measurement of SRL processes and strategies. As a result, we implemented multiple embedded case studies - courses - in accordance with the SRPBL approach for different topics, levels, and disciplines as follows:

- Knowledge Management, MSc in Business Information Management.

- Electronic Commerce, BSc in International Trade.

- Translation of Technical Text - English, BSc in Counseling, and Translation.

- Information Technology and Web Business, MSc in Hotel Management

\subsection{Sample and participants}

The study was conducted during the period from February 14th until April 15th of the second semester of the academic year 2018-2019 at the Superior Institute of Accountancy and Administration of the Polytechnic of Porto (ISCAP). With the collaboration of professors from the institute, four curricular courses have been adapted according to the flipped project-based learning approach (SRPBL). In the beginning, $\mathrm{N}=$ 120 is the total of students enrolled in the platform for four curricular online courses via the SRPBL platform. Five professors have participated in the planning, structuring, conducting, and evaluating their courses. The professors adopted the roles of facilitators throughout the different course activities.

However, participation in the study was voluntary, and students could withdraw anytime from the study. Students already enrolled in the courses were explicitly and voluntarily invited to participate in the study by filling the pretest and posttest questionnaires at the first and the last "in class" session. Only the students who completed all their courses' activities and filled the pretest and posttest questionnaires were conditionally considered and included in this study. In other words, to examine the impact of our approach, we included in the study only the participants that we could measure their initial and final self-regulated learning strategies.

As a result, the number of students how dropped out the study and did not respond to the pre and post questionnaires is $\mathrm{R}=120-84=36(30 \%)$. Even the students who did not participate in the study, they have been pursuing the courses they enrolled via 
the platform. We have not investigated the motifs why students dropped out as it is not part of the purpose of the present study. In this sense, it is important to mention that most students were excluded automatically from the study since the beginning as they did not voluntarily fill the pretest questionnaire.

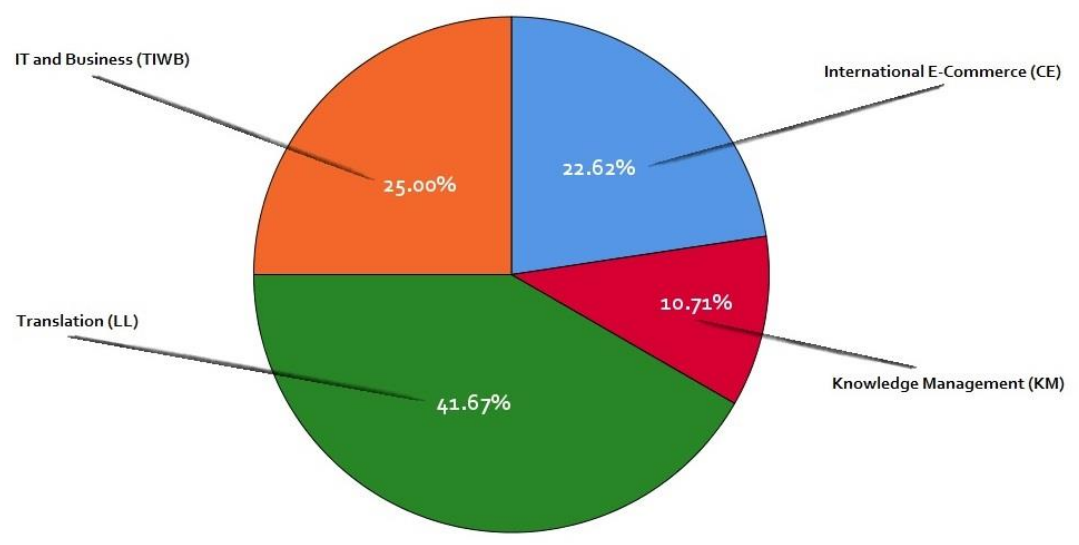

Fig. 1. Distribution of student groups.

In the end, we got a total of $n=84$ students who participated in the study distributed as follows and shows "see Figure 1":

- Knowledge Management (KM): (09) Students (22.6\%), and (01) Facilitator.

- Translation (LL): (35) Students (41.7.6\%), and (02) Facilitators.

- International E-Commerce (CE): (19) Students (22.6\%), and (01) Facilitator.

- IT and Business (TIWB): (21) Students (25\%), and (01) Facilitator.

\subsection{Instruments and measurements}

For the measurement of the students' self-regulated learning strategies, we used the SRPBL questionnaire. It is an adapted self-report instrument that mainly based on the MSLQ [30] and the Online Self-Regulated Learning Questionnaire (OSLQ) for measuring self-regulation in online and blended learning environments [31]. Besides, the proposed SRPBL questionnaire is the combination of further dependent questionnaires in order to cover all factors that may influence the development of selfregulation strategies. In the present study, we focused on the main three SRL facets related to the research questions: (motivation, self-regulation, and collaboration). Specifically, the SRPBL questionnaire used in this study is primarily composed of three sections (constructs), a section consists of an educational construct which is composed of a set of homogenous components (scales) and is defined by a set of items (questions). A five-sections typology of the SRPBL questionnaires is defined as follows: 
- Motivational beliefs

- Motivational Beliefs (11 items)

- Self-regulation Strategies (27 items)

- Collaborative Strategies (09 items)

Besides, we conducted structured interviews and surveys with the participants (students and facilitators) to find out their perceived reflections regarding the effectiveness of the approach on their engagement and satisfaction, in addition to the role of the instructional facilitation throughout flipped PBL activities.

\subsection{Flipped project-based learning approach (SRPBL)}

The proposed approach for flipped project-based learning is based on the theoretical framework of self-regulated project-based learning in higher education (SRPBL) [32]. The SRPBL framework as part of the approach is essential, whether the ensuing case study's purpose is to develop or to test such a theory. The SRPBL approach later becomes the vehicle for designing and conducting cases accordingly. The SRPBL approach describes the process of several PBL activities to carry out. It is multidimensional (cognitive, metacognitive, affective, and social) and cyclical as it takes place in three main phases: forethought phase, performance phase, and reflection phase. Each phase is a dynamic and reciprocal set of individual and/or collective activities. An activity is a step in a phase that is defined by tools, strategies, and outcomes.

The four courses of this study have been designed and conducted as an embedded multiple embedded case studies design [33]. The case study teaching is a powerful student-centered teaching strategy that can actively impart students with collaboration and metacognition (Barnes and al. 1994). Following the recommendations of Yin [33], the design of the proposed approach (SRPBL) is more about protocol than the instrument. It consists of the development of the rules and procedures contained in the protocol to enhance the reliability of case study research.

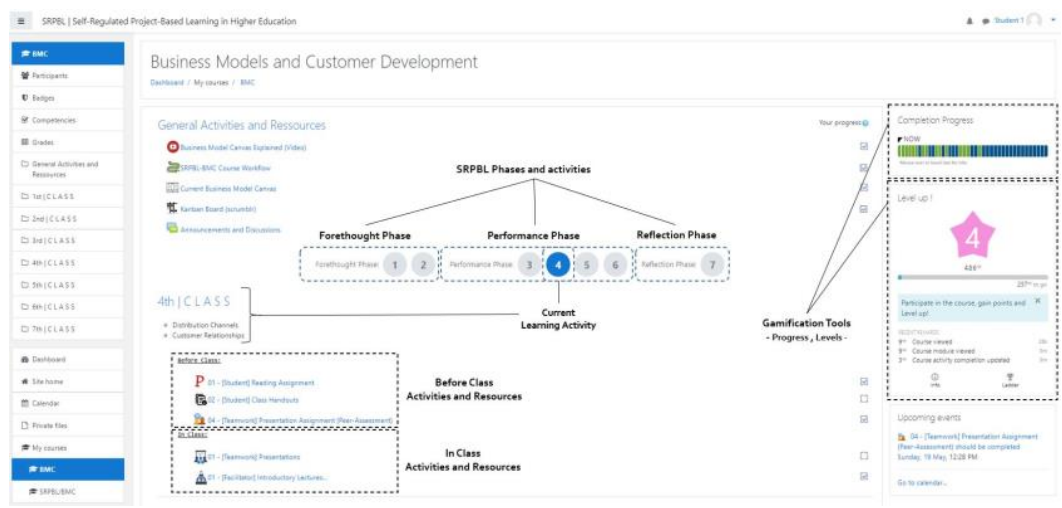

Fig. 2. The interface of the Flipped Project-Based Learning Environment. 
We used an LMS Moodle 3.4 for the implementation of the flipped project-based learning approach. A dedicated Moodle-based learning environment (SRPBL platform) was deployed and fully customized for the operationalization of the approach. The SRPBL platform is a flipped project-based learning environment according to the designing principles and assumptions for designing a student-centered learning environment [34], and taking into consideration of the determinant factors that sup-port self-regulated learning in blended learning suggested by S.Van Laer \& J. Elen [35].

During several meetings with facilitators ahead of the courses conducting, we explained in-depth the principle behind our approach and how it is being implemented and administered. We provide involved facilitators with the necessary detailed handouts to make smooth the adaptation of their curricular material to the proposed approach and for setting up of courses into the platform. All the course material and the instruments used for this study previously presented were upload and centralized on the platform. Each student could self-enroll in the platform and later approved by their facilitator. Before each class, students are invited to consult the necessary material of the in-class session before getting in. Then, students submit their weekly assignments and final outcomes individually and in groups via the tool. In addition to the in-class discussion, students could exchange their ideas, share their thoughts, seek help for their doubts and reflect on their and others' ideas via the tool of communication and collaboration via the platform.

A detailed description of the specific structure, workflow process, and specific roadmap of different activities of the courses conducted in this study have already fully described in our prior work on the implementation of flipped project-based learning for entrepreneurship education [36].

\section{Results}

\subsection{Internal reliability of SRPBL questionnaire}

We used Cronbach's Alpha to measure the internal consistency and reliability of the SRPBL questionnaire. It is most commonly used when we have multiple Likert questions in a questionnaire that form a set of scales and constructs. The questionnaire was employed to measure different underlying scales. A set of scales that contribute to three constructs: motivational beliefs, self-regulation strategies, and collaborative strategies. There were 84 cases (participants) included, and no cases were excluded due to missing values. As a result, all cases were valid (100\%). All scales had a high level of internal consistency, as determined by a Cronbach's alpha of [0.8 -0.9$]$.

3.2 RQ1: Does the flipped project-based learning approach foster students' self-regulated learning skills: motivational beliefs, self-regulation strategies, and collaborative strategies in higher education?

In addressing the first research question, we applied the paired samples t-test to examine the impact of the SRPBL approach on the four groups of participants consid- 
ered together as a single population. In other words, we wanted to determine if there are changes in the scores of all dependent variables of self-regulated learning strategies between two related groups. In this instance, the two "related groups" are the same population that is tested in at two "time points": pretest and posttest.

Namely, there are three main strategies as constructs: self-motivational beliefs, self-regulation strategies, and collaborative strategies. Each construct is defined by a set of sub-scales as presented "see Table 1".

Table 1. Statistical Comparisons - Paired Samples T-Test Results

\begin{tabular}{|c|c|c|c|c|c|c|c|c|c|}
\hline \multirow{2}{*}{\multicolumn{2}{|c|}{$\begin{array}{c}\text { Paired of } \\
\text { Constructs/Scales }\end{array}$}} & \multirow{2}{*}{ Mean } & \multirow{2}{*}{ Std. } & \multicolumn{3}{|c|}{ Paired Differences } & \multirow{2}{*}{$\mathbf{t}$} & \multirow{2}{*}{ df } & \multirow{2}{*}{ Sig. } \\
\hline & & & & $M$ & Std. & $d$ & & & \\
\hline \multicolumn{10}{|c|}{ Motivational Beliefs } \\
\hline \multirow[t]{2}{*}{ Motivational Beliefs } & Post & 2.67 & 0.68 & \multirow{2}{*}{0.43} & \multirow{2}{*}{0.77} & \multirow{2}{*}{0.56} & \multirow{2}{*}{5.16} & \multirow{2}{*}{83} & \multirow{2}{*}{0.000} \\
\hline & Pre & 2.23 & 0.73 & & & & & & \\
\hline \multicolumn{10}{|c|}{ Self-Regulation Strategies } \\
\hline \multirow{2}{*}{$\begin{array}{l}\text { Before } \\
\text { Learning }\end{array}$} & Post & 2.56 & 0.60 & \multirow{2}{*}{-0.02} & \multirow{2}{*}{0.54} & \multirow{2}{*}{-0.04} & \multirow{2}{*}{-0.37} & \multirow{2}{*}{83} & \multirow{2}{*}{0.716} \\
\hline & Pre & 2.58 & 0.56 & & & & & & \\
\hline \multirow[t]{2}{*}{ During Learning } & Post & 2.85 & 0.51 & \multirow{2}{*}{0.34} & \multirow{2}{*}{0.46} & \multirow{2}{*}{0.73} & \multirow{2}{*}{6.70} & \multirow{2}{*}{83} & \multirow{2}{*}{0.000} \\
\hline & Pre & 2.51 & 0.48 & & & & & & \\
\hline \multirow[t]{2}{*}{ After Learning } & Post & 2.62 & 0.59 & \multirow{2}{*}{0.12} & \multirow{2}{*}{0.57} & 021 & 105 & 82 & 0054 \\
\hline & Pre & 2.50 & 0.49 & & & 0.21 & 1.95 & 83 & 0.054 \\
\hline Timon & Post & 2.48 & 0.46 & 020 & 046 & 060 & 4 & 82 & ( \\
\hline I ime Management & Pre & 2.16 & 0.35 & 0.32 & 0.40 & 0.69 & 0.34 & 83 & 0.000 \\
\hline EnvironmentStructur- & Post & 2.67 & 0.51 & 038 & 032 & 117 & 1070 & 83 & 0000 \\
\hline & Pre & 2.30 & 0.44 & 0.50 & 0.32 & 1.17 & $10 . / 0$ & 05 & 0.000 \\
\hline Regulation & Post & 2.68 & 0.57 & 024 & 0.54 & 044 & 401 & 83 & $0 \Omega 00$ \\
\hline Persistence & Pre & 2.44 & 0.52 & 0.24 & 0.24 & 0.44 & 4.01 & 83 & 0.000 \\
\hline & & & rative & tegies & & & & & \\
\hline Help Seeking & Post & 2.24 & 0.56 & 041 & 0 & 0.83 & 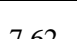 & 83 & $0 \Omega$ \\
\hline & Pre & 1.83 & 0.42 & 0.41 & 0.47 & $0.0 J$ & 1.02 & OJ & 0.000 \\
\hline Peer Learning & Post & 1.89 & 0.62 & 023 & 0.64 & 036 & 332 & 83 & 0001 \\
\hline & Pre & 1.66 & 0.38 & $0.2 \mathrm{~J}$ & 0.04 & 0.00 & J.J2 & OJ & 0.001 \\
\hline
\end{tabular}

In short, the results revealed that the flipped project-based learning approach significantly improved students' motivational beliefs, and the use of self-regulation strategies and collaborative strategies.

Motivational beliefs: the results of the paired-samples test indicated that students as a whole, got more motivated after completing their SRPBL courses in comparison to their prior motivational beliefs, a statistically significant mean increase of $M=0.43, \mathrm{t}$ $=6.35, \mathrm{p}<.005$, and a medium to large effect of $d=0.75$.

Effects on self-regulation strategies: Similarly, we found a statistically significant mean difference $(\mathrm{p}<0.05)$ regarding almost all collective dependent variables (subscales) of Self-regulation strategies: During Learning $(\mathrm{M}=0.34, \mathrm{t}=6.70$, and large effect of $d=0.73)$, Time Management $(M=0.31 \mathrm{t}=6.340$, medium effect of $\mathrm{d}=$ $0.69)$, Environment Structuring $(\mathrm{M}=0.37, \mathrm{t}=10.70$, large effect of $\mathrm{d}=1.17)$, and Persistence $(M=0.24, t=4.01$, and small effect of $d=0.44)$. Alternatively, students 
reported a no statistically significant positive increase $(\mathrm{M}=0.12, \mathrm{t}=1.96$, and small effect of $d=0.21$ ) in relation with After Learning sub-scale. The exception is the Before Learning sub-scale, there was no statistically significant difference in addition to a negative effect $(M=-0.020 .02, t=-0.36$, and negative small effect of $d=-0.04)$ after the intervention.

Effects of collaborative strategies: besides, results revealed a positive effect of the proposed approach on students' collaborative strategies. There were a statically significant mean differences for de-pendent variables: Help-Seeking $(\mathrm{M}=0.41, \mathrm{t}=$ 7.61, and large effect of $\mathrm{d}=0.83)$ and Peer Review $(\mathrm{M}=0.23, \mathrm{t}=3.32$, and small effect of $d=0.36$ ).

\subsection{RQ2: Does the flipped project-based learning approach foster students' SRL skills between groups across different disciplines and levels?}

In addressing the second research question, A one-way ANOVA was conducted to determine if the gains of different scales and constructs of self-regulated learning strategies were different between the different groups of students. The dependent variables would be SRL performance defined by the gain scores recorded of related constructs: motivational beliefs, self-regulation, and collaboration measured via the pretest and the posttest SRPBL questionnaires. The independent variable would be the students' group. In addition to the descriptive statistics results presented "see Table 2", The assumption of homogeneity of variances is tested using Levene's test of equality of variances. There was homogeneity of variances only for 'motivational beliefs' and 'collaborative strategies' scales. Alternatively, a one-way Welch ANOVA was conducted to determine if the ability gain score of 'self-regulation strategies, as the assumption of homogeneity of variances was violated assessed by Levine's test ( $p=$ $0.002)$.

Table 2. Comparisons Between Groups - One Way ANOVA Test - Descriptive Statistics

\begin{tabular}{|c|c|c|c|c|c|c|c|c|c|}
\hline \multirow{2}{*}{$\begin{array}{l}\text { Constructs } \\
\text { (Gains) }\end{array}$} & \multirow[t]{2}{*}{ Group } & \multirow[t]{2}{*}{$\mathbf{N}$} & \multirow[t]{2}{*}{ Mean } & \multirow[t]{2}{*}{ Std. } & \multirow{2}{*}{$\begin{array}{l}\text { Std. } \\
\text { Error }\end{array}$} & \multicolumn{2}{|c|}{$\begin{array}{c}95 \% \text { C. Interval for } \\
\text { Mean }\end{array}$} & \multirow[t]{2}{*}{ Min } & \multirow[t]{2}{*}{ Max } \\
\hline & & & & & & Lower & Upper & & \\
\hline \multirow{4}{*}{$\begin{array}{l}\text { Motivational } \\
\text { Beliefs }\end{array}$} & CE & 19 & 0.03 & 0.55 & 0.13 & -0.24 & 0.29 & -1.18 & 1.18 \\
\hline & KM & 9 & -0.25 & 0.53 & 0.18 & -0.66 & 0.16 & -1.03 & 0.70 \\
\hline & LL & 35 & 1.08 & 0.63 & 0.11 & 0.86 & 1.29 & -0.57 & 2.79 \\
\hline & TIWB & 21 & 0.03 & 0.39 & 0.09 & -0.15 & 0.20 & -0.55 & 0.73 \\
\hline \multirow{4}{*}{$\begin{array}{l}\text { Self-Regulation } \\
\text { Strategies }\end{array}$} & CE & 19 & 0.17 & 0.23 & 0.05 & 0.06 & 0.28 & -0.07 & 0.73 \\
\hline & KM & 9 & 0.19 & 0.33 & 0.11 & -0.06 & 0.45 & -0.24 & 0.62 \\
\hline & LL & 35 & 0.42 & 0.41 & 0.07 & 0.28 & 0.56 & -0.45 & 1.21 \\
\hline & TIWB & 21 & -0.02 & 0.25 & 0.06 & -0.14 & 0.09 & -0.32 & 0.64 \\
\hline \multirow{4}{*}{$\begin{array}{l}\text { Collaborative } \\
\text { Strategies }\end{array}$} & CE & 19 & -0.28 & 0.35 & 0.08 & -0.45 & -0.11 & -0.75 & 0.75 \\
\hline & KM & 9 & -0.45 & 0.25 & 0.08 & -0.64 & -0.25 & -0.84 & -0.11 \\
\hline & LL & 35 & 0.37 & 0.39 & 0.07 & 0.24 & 0.50 & -0.36 & 1.08 \\
\hline & TIWB & 21 & -0.41 & 0.24 & 0.05 & -0.52 & -0.29 & -0.90 & 0.02 \\
\hline
\end{tabular}


As a result, there were statistically significant gain differences for students' motivational beliefs and their ability to work collaboratively between groups as determined by the one-way ANOVA test $(\mathrm{F}(3,80)=27.796, \mathrm{p}=0.000$ and, and $\mathrm{F}(3,80)$ $=33.321, \mathrm{p}=0.000$, respectively). Likewise, Welch's ANOVA revealed a statistically significant gain difference for self-regulation strategies between groups $(\mathrm{F}(3,29.853)$ $=7.975, \mathrm{p}=.000$ ). Eventually, we concluded that the flipped, project-based learning approach had a positive effect on student groups' self-regulated learning strategies, but significantly different depending on the group's characteristics and specific domains of courses. These results Initially confirmed that the development of selfregulated strategies in contextual, domain-specific, and influenced by the characteristic of learners and learning environments. From the results so far, we already know that there are statistically significant differences between the groups as a whole. However, as the one-way ANOVA is an omnibus test, we needed to run further multiple comparisons to shows particularly which groups differed from each other. to do so, we used the graphical method as it illustrated "see Figures 2, 3, and 4".

The mean changes between different groups and scales (pretest and posttest) become more apparent when we consult the bar graphs. Results are presented by dependent scales of self-regulated strategies: motivational beliefs, self-regulation strategies, and collaborative strategies.

Comparisons on motivational beliefs between groups: While we can notice from the chart "see Figure 3" a decrease in motivational beliefs score for the group 'KM' (n $=9, \mathrm{M}=-0.25, \mathrm{SD}=0.53)$, on the contrary, students' motivational beliefs increased positively from $(\mathrm{n}=21, \mathrm{M}=0.03, \mathrm{SD}=0.39)$ for ' $T I W B$ ' group, to $(\mathrm{n}=19, \mathrm{M}=$ $0.03, \mathrm{SD}=0.55)$, 'CE' group, to $(\mathrm{n}=35, \mathrm{M}=1.08, \mathrm{SD}=0.63)$, and ' $\mathrm{LL}$ ' group, in that order.

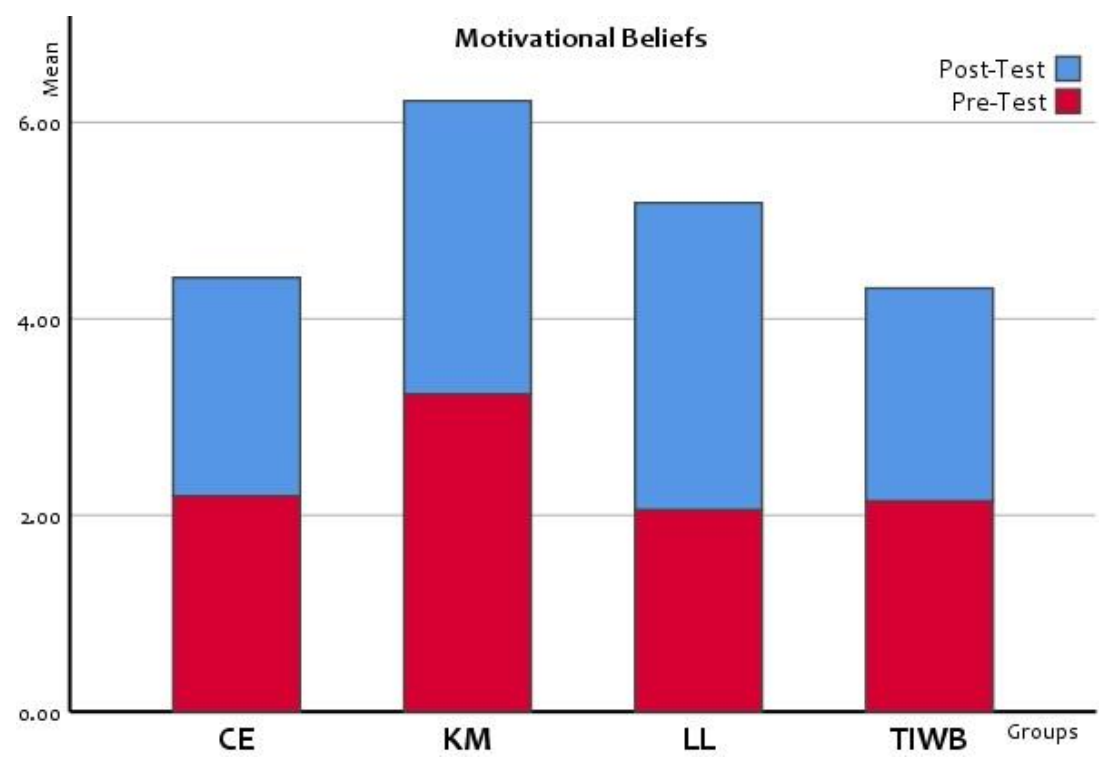

Fig. 3. Stacked Bar Mean of (motivational beliefs) posttest and pretest by groups. 
Comparisons on Self-Regulation Strategies between Groups: the chart "see Figure 4" shown that there was an increase in regulation strategies scores from $(\mathrm{M}=0.17$, $\mathrm{SD}=0.23)$ for ' $\mathrm{CE}$ ' group, to $(\mathrm{M}=0.19, \mathrm{SD}=0.33)$ for ' $\mathrm{KM}$ ' group, to $(\mathrm{M}=0.42$, $\mathrm{SD}=0.41)$ for ' $L L$ ' group respectively. Otherwise, there was a decrease in regulation/learning strategies score of $(\mathrm{M}=-0.02, \mathrm{SD}=0.25)$ for TIWB group.

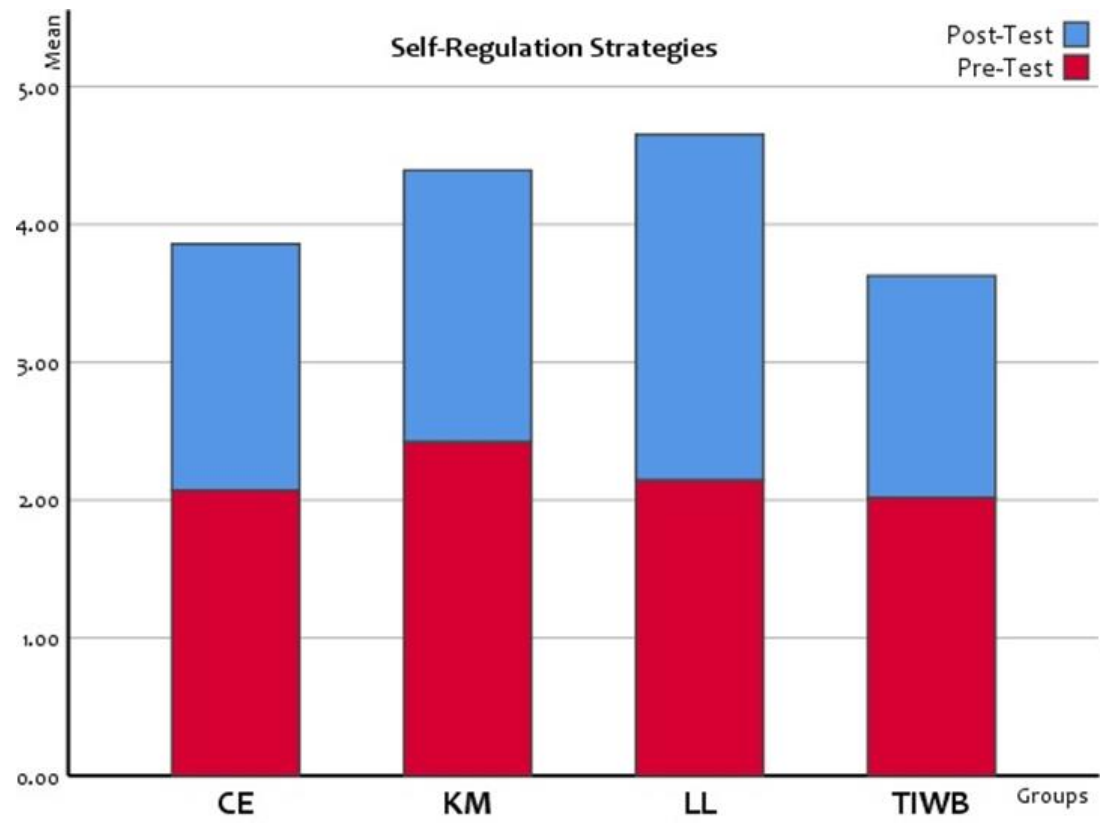

Fig. 4. Stacked Bar Mean of (self-regulation strategies) posttest and pretest by groups

Comparisons on Collaborative Strategies between Groups: the chart "see Figure 5" shown that there was an increase in collaborative strategies score only of $(M=0.37$, $\mathrm{SD}=0.39)$ in ' $L L$ ' group. On the contrary, students' collaborative strategies scores negatively decreased from $(\mathrm{M}=-0.28, \mathrm{SD}=0.35)$ in ' $\mathrm{CE}$ group, to $(\mathrm{M}=-0.40, \mathrm{SD}=$ $0.24)$ in 'TIWB group, to $(\mathrm{M}=-0.45, \mathrm{SD}=0.25)$ in ' $\mathrm{KM}$ ' group, in that order. 


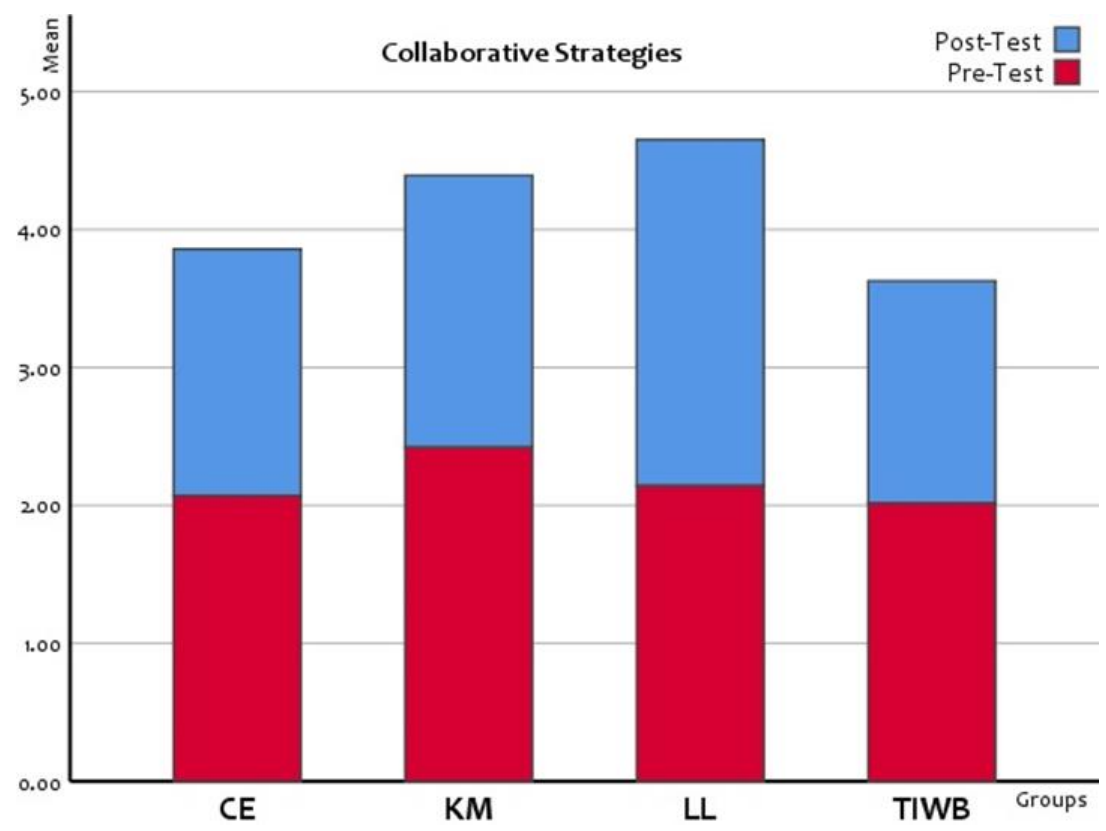

Fig. 5. Stacked Bar Mean of (collaborative strategies) posttest and pretest by groups

\section{Discussions, Limitations and Conclusions}

\subsection{Discussions and implications}

In this study, we examined the impact and the effectiveness of a flipped projectbased learning approach (SRPBL) on students' self-regulated learning: motivational beliefs, self-regulation strategies, and collaborative strategies. We adopted a quasiexperiment study design. Mixed data were coupled to genuinely address the research questions and form a holistic understanding of students' changes in self-regulation performance, and facilitators' reflections on the SRPBL approach itself and the challenges experienced.

Taken as a whole, it was found that the proposed approach significantly improved students' self-regulated learning skills. Moreover, the findings reported in this study support the hypothesis that an increase in SRL skills as an effective outcome of engagement of participants with the approach which aims to explicitly support and strengthen these competencies. The results suggest that when learners are actively engaged in their PBL activities, they report significant increases in their motivational beliefs and self-regulation strategies. Properly, quantitative data confirmed that students performed better in the post-test questionnaires than in the pre-test. The pairedsample test revealed a significant difference in mean total scores of students' selfregulated learning skills at the end of the study $(p<0,05)$. These results were consistent with qualitative data obtained from the interview and facilitator judgment, both 
with students and facilitators. The data acquired from respondents revealed a notable engagement and satisfaction with the proposed approach. Similarly, it claimed that PBL environments foster students' motivation and self-regulatory skills [37].

The results of the paired samples t-test which was done in the relation to the first research question showed that there is a statistically significant mean difference ( $\mathrm{p}<$ 0.05 ) and a medium to large positive effect between the means of our two related groups (i.e., pre-test and post-test) in terms of motivational beliefs, self-regulation strategies, and collaboration strategies. In other words, when students got motivated (task value, goal orientation, task value, expectancy, self-efficacy), they engaged actively throughout their learning activities (during learning strategies) using their self-regulation strategies such time management, environment structuring, and persistence, that brought them to feel more comfortable to seek help (help-seeking) and become more interactive and learn with their peers (peer learning).

However, we noticed that even students felt comfortable reaching out to their peers and seek help; they did not report higher peer learning benefits (peer learning). It may be noticed that the impact of the facilitators, in this case, is more effective on their learning incomes. Moreover, the approach had no significant effect on students' some metacognitive strategies such as before learning (negative effect) and after learning (minimal effect). That could be explained by taking into consideration that most of the participants $(79.8 \%)$ have never experienced any online curricular course before or at least a similar PBL course that supports SRL. So, it will be meaningful to measure theirs before and after learning strategies in future similar learning experiences. In this sense, we did not allow students to state explicitly their learning objectives before each course. We considered that all or most participants did not have experience with this type of learning and provided them with predefined learning objectives in advance. Thus, that may imply when students are allowed to set their goals, they will obviously be able to develop their metacognitive strategies (before learning) for further learning experiences.

Overall, it may be concluded that flipped project-based learning has a positive impact on enhancing higher education students' motivational beliefs, self-regulation strategies, and collaborative strategies over the in-class and out of class activities. In the line, studies revealed that when students engage actively in self-regulated learning when they get into learning opportunities that require a high level of complexity of cognitive processing. Where they participate in ill-defined and open-ended activities, working work together on authentic learning projects, brainstorm and integrate ideas that go beyond the material presented to co-construct new knowledge, make decisions within groups, make choices that influence their learning outcomes, and evaluate themselves and their peers [37].

With regard to the second research question, the one-way ANOVA test indicated that learners during different SRPBL courses improved their self-regulated learning strategies significantly. That means the approach could foster students' regulation performance, whatever the subject core course or the participants' disciplines. The approach affects students' self-regulation as a meta layer beyond the subjects of the courses being accredited. A key finding in this regard, the KM group, approached their course a bit more motivated (Mean $=3.23$ ) with higher expectations that other 
groups (Means $=2.14$ to 2.20 ). This is because they have already experienced a similar course according to the proposed approach in the first semester as a pilot case study of this research. Even that, they got less motivated at the end of the second learning experience. It may be said that the second courses were not in their expectations in relation to their first experience. We also think that may be related to external factors affecting their engagement and motivation in such a learning experience. We hypothesized that the instructional facilitation of their teachers or the quality of the project being talked in their cases as teamwork projects potential causes. That why these two factors, among others, are the subject of investigation of a complementary study of this current paper.

Generally, all the groups reported an increase in their motivational beliefs. Notably, the LL group reported the higher scores mean of their motivational beliefs. Namely, this group course the only one that was conducted by two facilitators instead of one, additionally they claimed in the survey and interviews responses a high level of satisfaction and usefulness about the approach. They appreciated the way how the course was designed and conducted by each teamwork with specific roles and tasks. They worked similarly on authentic cases of translation. Likely, the LL group significantly improved their self-regulation and collaboration strategies in comparison with other groups. Therefore, we can conclude that the quality of the course design being tackled in a flipped PBL in addition to effective instruction facilitation has a remarkable impact on students' motivation and engagement. These findings are consistent with similar results suggesting that the good structuration flexibility of teaching design can promote students' active learning behaviors and teamwork spirit [38], [39].

Regarding the self-regulation strategies, all groups developed their skills in this regard, except the TIWB group. Similarly, the L group gain a high increase in their scores mean of self-regulation strategies. Only the LL group reported a higher increase in their collaboration strategies.

In summary, the centeredness of student offered by the flipped PBL environment, the flexibility of learning activities, the well designed in-class and out-of-class activities, effective instructional facilitation and conduction of involved teachers, and similar accumulative experiences were all important and determinant factors fostering student's self-regulation performance among their specific disciplines. Additionally, it may be said that when students engage actively and effectively in teamwork activities, they mutually develop their SRL skills. Consequently, there is a dialectical causeeffect relationship among the three main factors in relation to self-regulated learning which are: motivational beliefs, self-regulation strategies, and collaboration strategies. Furthermore, we noticed that students had some doubt and uncertainty about the PBL method at the beginning, but they have got comfortable gradually. In this regard, the instructional facilitators and characteristics of learning environments may foster students' gain of self-regulated learning skills [40]. Facilitators should be provided with practical handouts so that they can become boosters of self-regulated learners. This finding is coherent with studies, who found that creative instructional practices used in the teaching, such as gamified flipped classroom and project-based learning reinforced students' self-regulated and autonomous learning and improved their motivation [41]. The results of this study were in line with other research [42], which as- 
sessed the effectiveness of integrated curricular blended PBL to promote SRL skills in higher education, but also suggested the need to involve instructors in the training to increase its effectiveness. In other words, being able to plan, monitor, and evaluate a learning activity does not automatically imply that one can orient and direct one's learning process without the support and guidance of teachers as facilitators [40].

The qualitative findings of the surveys and interviews with participants (students and facilitators) appeared to support the quantitative findings. The statements of students shown some evidence of flipped PBL's influence on all levels of motivation and engagement. Students claimed that they learned and interact with each other more during flipped PBL activities, and they attributed this to the hands-on classroom activities, and the opportunity to share information among teamwork members. Moreover, according to the qualitative data of the interviews and survey responses in terms of perceived ease of use and usefulness, our approach was found to be more useful, more effective for most students and facilitators as well. Besides, the students showed better collaborating behaviors and greater satisfaction. The students' comments (especially LL group) on working in groups once again suggest that PBL's contribution to preparing students for their future working life, where they will be required to work in a collaborative team environment. However, the student participants, as well as facilitators have had some comments on its implementation with the absence of tutoring rooms, it was difficult for students to meet outside of class. Indeed, the number of courses they had in their academic year and personal engagement of some students left them not much time for their individual and group work. Similarly, Given the heavy workload and the breadth of the course content, facilitators suggested longer courses. Certainly, the course should be restructured in order to cover the theories and applications related to core knowledge testing and evaluation, and enough time should be spared for such purpose. Similarly, researchers found that flipped learning methods help students to be more independent and take more control over their own learning process [43].

Important implications could be drawn from this research for the design of effective flipped project-based learning fostering self-regulated learning, supported by the empirical results obtained. The main contribution was that our proposed approach could provide a meta-layer of the iterative learning processes to promote students' self-regulative abilities. These kinds of integrated curricular programs make it possible to promote the skills currently required by the new learning and teaching paradigm in higher education, such as proactivity, time management, problem-solving, and teamwork. The findings of this study showed that integrated, explicit, and contextualized support for SRL strategies may improve student learning on the transition to the flipped PBL context. The implications point out to the need for a transitional strategy to lifelong learning that integrates these kinds of student-centered activities to help learners understand and implement effective learning strategies.

\subsection{Limitations}

The present study examined the effect of flipped PBL on the SEL skills of higher education students. However, the research has some limitations. 
Instructional facilitation role and short-period case studies application: The fact that the facilitators were confronted for the first time with a flipped teaching method - as a new teaching method - may be the reason why they did not have a significant effect on their students' self-regulated learning skills and their adaptive pedagogical facilitation to this effect. Another considerable reason could be that the period of application devoted to the courses may not have been sufficient for the development of their self-regulated learning skills. Studies found that the in-depth development of self-regulation occurred only after a long period of accumulative learning experiences. It appears that better experiences of the development of SRL skills could be obtained through a long-term study ranging from one semester to a few academic years [44].

Impact of the proposed approach on student's performance: Training students to self-regulate their learning within a flipped project-based learning environment seems to lead to significant increases in their understanding of their specific subjects. Although, we did not investigate the effect of the flipped PBL on students' academic achievement along with their self-regulatory skills. We suggest this focus as the next step for further work.

The self-report instrument to measure self-regulated learning: Self-regulated learning (SRL) is a growing theoretical field. Nevertheless, assessing SRL processes is still an ongoing debate. Despite the numerous studies which use them, their reliability to assess SRL processes is today regularly questioned. Empirical pieces of evidence have shown that students are generally bad estimators of both their behavior and cognitive activity. Taking into consideration these facts, more and more claims are made to complete those offline measures by online measures; in other words, measures that capture SRL processes when they occur [45]. This requires more research to understand the interdependence and dynamics of SRL variables, as well as the contextual factors deployed during the cyclical and iterative phases of the learning process [46]. To do so, this current study is the basis of an ongoing work that consists of exploiting the obtained results analysis and implications for the aim to design an integrated learning analytics framework supporting self-regulated project-based learning processes.

\subsection{Conclusion}

The growing implementation of technology in the pedagogical process has already has driven to a drastic paradigm shift in teaching and learning methods. This has led to a growing trend to integrate recent technologies to create a useful, encouraging, and engaging student-centered learning environment to enhance students' lifelong skills while dealing with authentic learning projects. In this sense, flipped PBL, as an effective student-centered educational practice, tends to have a considerable impact on students' self-regulation abilities and all levels of higher education and across different disciplines. 


\section{$5 \quad$ Acknowledgement}

The authors gratefully acknowledge ISCAP Professors M.J. Gonçalves, M.G.

Chorão, S. Ribeiro, and C. Silva for their valuable contributions to this work.

\section{References}

[1] E. Fuson, "Project Management Skills \& PBL," Project Management Primer for Community Conversation. http://projectmanagement.p21.org/ (accessed Dec. 15, 2017).

[2] S. Chu, al., "Twenty-First Century Skills and Global Education Roadmaps," in 21st Century Skills Development Through Inquiry-Based Learning, Springer, 2017. https://doi.org/ 10.1007/978-981-10-2481-8_2

[3] C. Dasgupta, A. Magana, \& C. Vieira, "Investigating the affordances of a CAD enabled learning environment for promoting integrated STEM learning," Comput. Educ., 2019. https://doi.org/10.1016/j.compedu.2018.10.014

[4] D. Ifenthaler, "Determining the effectiveness of prompts for self-regulated learning in problem-solving scenarios," J. Educ. Technol. Soc., vol. 15, no. 1, pp. 38-52, 2012.

[5] S. Hoidn, "Situative Educational Model for the Design of Powerful Student-Centered Learning Environments," in Student-Centered Learning Environments in Higher Education Classrooms, S. Hoidn, Ed. New York: Palgrave Macmillan US, 2017, pp. 341-409. https:// doi.org/10.1057/978-1-349-94941-0_6

[6] R. A. Dixon and R. A. Brown, "Transfer of Learning: Connecting Concepts during Problem Solving.," J. Technol. Educ., vol. 24, no. 1, pp. 2-17, 2012.

[7] X. Ge and B. L. Chua, "The Role of Self-Directed Learning in PBL," in The Wiley Handbook of Problem-Based Learning, John Wiley \& Sons, Ltd, 2019, pp. 367-388. https://doi. org/10.1002/9781119173243.ch16

[8] S. Sungur and C. Tekkaya, "Effects of problem-based learning and traditional instruction on self-regulated learning," J. Educ. Res., vol. 99, no. 5, pp. 307-320, 2006. https://doi. org/10.3200/joer.99.5.307-320

[9] S. Oates, "The importance of autonomous, self-regulated learning in Primary Initial Teacher Training," in Frontiers in Education, 2019, vol. 4, p. 102. https://doi.org/10.3389/ feduc. 2019.00102

[10] P. R. Pintrich, "The role of goal orientation in self-regulated learning," in Handbook of self-regulation, Elsevier, 2000, pp. 451-502. https://doi.org/10.1016/b978-012109890-2/5 $\underline{0043-3}$

[11] B. J. Zimmerman, "Becoming a self-regulated learner: An overview," Theory Pract., vol. 41, no. 2, pp. 64-70, 2002.

[12] S. Loyens, J. Magda, and R. Rikers, "Self-Directed Learning in Problem-Based Learning and its Relationships with Self-Regulated Learning," Educ. Psychol. Rev., Dec. 2008. https ://doi.org/10.1007/s10648-008-9082-7

[13] P. A. Alexander, Why this and why now? Introduction to the special issue on metacognition, self-regulation, and self-regulated learning. Springer, 2008. https://doi.org/10.1007/s1 $\underline{0648-008-9089-0}$

[14] M. Boekaerts and L. Corno, "Self-regulation in the classroom: A perspective on assessment and intervention,” Appl. Psychol., vol. 54, no. 2, pp. 199-231, 2005. 
[15] M. D. Endedijk, and al., "Measuring students' self-regulated learning in professional education: bridging the gap between event and aptitude measurements," Qual. Quant., Sep. 2016. https://doi.org/10.1007/s11135-015-0255-4

[16] B. J. Zimmerman and M. Campillo, "Motivating self-regulated problem solvers," Psychol. Probl. Solving, pp. 233-262, 2003. https://doi.org/10.1017/cbo9780511615771.009

[17] P. C. Blumenfeld, and al. "Motivating project-based learning: Sustaining the doing, supporting the learning," Educ. Psychol., vol. 26, no. 3-4, pp. 369-398, 1991. https://doi.org/ 10.1207/s15326985ep2603\&4_8

[18] T.-Y. Mou, "Students' Evaluation of Their Experiences with Project-Based Learning in a 3D Design Class," Asia-Pac. Educ. Res., pp. 1-12, 2019.

[19] C. Karaca and M. Ocak, "Effect of flipped learning on cognitive load: A higher education research," J. Learn. Teach. Digit. Age, vol. 2, no. 1, pp. 20-27, 2017.

[20] T. I. Oweis, "Effects of using a blended learning method on students' achievement and motivation to learn English in Jordan: A Pilot Case Study," Educ. Res. Int., vol. 2018, 2018. https://doi.org/10.1155/2018/7425924

[21] A. Al-Huneidi and J. Schreurs, "Constructivism based blended learning in higher education," in World Summit on Knowledge Society, 2011, pp. 581-591. https://doi.org/10.10 07/978-3-642-35879-1_74

[22] C. L. Lim, H. Ab Jalil, A. M. Ma'rof, and W. Z. Saad, "Peer Learning, Self-Regulated Learning and Academic Achievement in Blended Learning Courses: A Structural Equation Modeling Approach,” Int. J. Emerg. Technol. Learn. IJET, vol. 15, no. 03, 2020. https:// doi.org/10.3991/ijet.v15i03.12031

[23] F. Paraskeva et al., "Applying PBL and SRL to Enhance Learning Strategies and Collaboration in a Blended Learning Environment," in International Workshop on Learning Technology for Education in Cloud, 2017, pp. 85-96. https://doi.org/10.1007/978-3-319-62743$\underline{4} 8$

[24] L. Abeysekera and P. Dawson, "Motivation and cognitive load in the flipped classroom: definition, rationale and a call for research," High. Educ. Res. Dev., vol. 34, no. 1, 2015. https://doi.org/10.1080/07294360.2014.934336

[25] C. Dziuban, C. Graham, P. Moskal, A. Norberg, and N. Sicilia, "Blended learning: the new normal and emerging technologies," Int. J. Educ. Technol. High. Educ., vol. 15, no. 1, 2018. https://doi.org/10.1186/s41239-017-0087-5

[26] V. Orfanakis, and al. "Digital student conference platform implementation: the case study

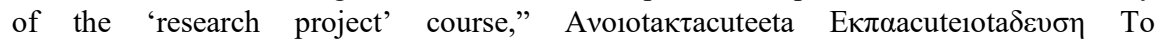

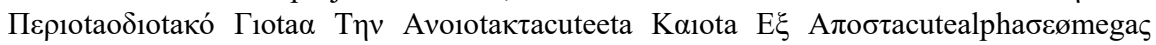

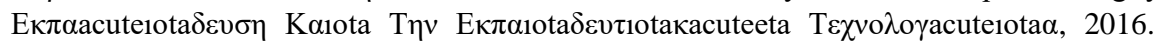
https://doi.org/10.12681/jode.10871

[27] S. Kardipah and B. Wibawa, "A Flipped-Blended Learning Model with Augmented Problem Based Learning to Enhance Students' Computer Skills," TechTrends, pp. 1-7, 2020. https://doi.org/10.1007/s11528-020-00506-3

[28] F. Paraskeva, and al. "Motivating Engineer Students in E-learning Courses with Problem Based Learning and Self-Regulated Learning on the apT2CLE4'Research Methods' Environment," in Learning Technology for Education Challenges, Cham, 2019, pp. 189-201. https://doi.org/10.1007/978-3-030-20798-4_17

[29] D. Onah, E. Pang, and J. E. Sinclair, "Cognitive optimism of distinctive initiatives to foster self-directed and self-regulated learning skills: A comparative analysis of conventional and blended-learning in undergraduate studies," Educ. Inf. Technol., Apr. 2020. https://doi.org/ $\underline{10.1007 / \mathrm{s} 10639-020-10172-\mathrm{w}}$ 
[30] P. R. Pintrich and E. V. De Groot, "Motivational and self-regulated learning components of classroom academic performance.," J. Educ. Psychol., vol. 82, no. 1, p. 33, 1990. https ://doi.org/10.1037/0022-0663.82.1.33

[31] L. Barnard, W. Y. Lan, Y. To, V. Paton, and S.-L. Lai, "Measuring self-regulation in online and blended learning environments," Internet High. Educ., vol. 12, no. 1, pp. 1-6, Jan. 2009.

[32] M. Y. Zarouk, F. Restivo, and M. Khaldi, "A Framework for Self-Regulated Project-Based Learning in Higher Education" in Educational and Social Dimensions of Digital Transformation in Organizations, IGI Global, 2019. https://doi.org/10.4018/978-1-5225-6261-0.ch0 $\frac{10}{R}$

[33] R. K. Yin, Case Study Research: Design and Methods, 5th Revised edition. Los Angeles London New Delhi Singapore Washington, DC: SAGE Publications Inc, 2013.

[34] C. Reigeluth, B. Beatty, \& R. Myers, Eds., The foundations and assumptions of technology-enhanced student-centered learning environments. London; New York: Routledge, 2017.

[35] S. Van Laer and J. Elen, "In search of attributes that support self-regulation in blended learning environments,” Educ. Inf. Technol., vol. 22, no. 4, pp. 1395-1454, Jul. 2017. https ://doi.org/10.1007/s10639-016-9505-x

[36] Y. Zarouk, M. J. Gonçalves, M. da G. Chorão, S. Ribeiro, C. Silva, and P. Peres, "FLIPPING PROJECT-BASED LEARNING FOR ENTREPRENEURSHIP EDUCATION,” ICERI Conference, Seville, Spain, Nov. 2019, pp. 394-404, https://doi. org/10.21125/iceri.2019.0135.

[37] S. Sungur and C. Tekkaya, "Effects of problem-based learning and traditional instruction on self-regulated learning," J. Educ. Res., vol. 99, no. 5, pp. 307-320, 2006. https://doi. org/10.3200/joer.99.5.307-320

[38] W.-L. Shih and C.-Y. Tsai, "Students' perception of a flipped classroom approach to facilitating online project-based learning in marketing research courses," Australas. J. Educ. Technol., vol. 33, no. 5, 2017. https://doi.org/10.14742/ajet.2884

[39] P. Sakulviriyakitkul, K. Sintanakul, and J. Srisomphan, "The Design of a Learning Process for Promoting Teamwork using Project-Based Learning and the Concept of Agile Software Development,” Int. J. Emerg. Technol. Learn. IJET, vol. 15, no. 03, pp. 207-222, 2020. https://doi.org/10.3991/ijet.v15i03.10480

[40] S. Temel, "The effects of problem-based learning on self-regulated learning skills and the variables predictive of these skills," Mediterr. J. Soc. Sci., vol. 4, no. 14, p. 297, 2013. https://doi.org/10.5901/mjss.2013.v4n14p297

[41] Z. Zainuddin, "Students' learning performance and perceived motivation in gamified flipped-class instruction," Comput. Educ., vol. 126, pp. 75-88, 2018. https://doi.org/10.10 16/j.compedu.2018.07.003

[42] P. Rosário, and al. "Processos de auto-regulação da aprendizagem em alunos com insucesso no 1. o ano de Universidade," Psicol. Esc. E Educ., vol. 14, no. 2, pp. 349-358, 2010. https://doi.org/10.1590/s1413-85572010000200017

[43] M. Y. Abdullah, S. Hussin, and K. Ismail, "Implementation of Flipped Classroom Model and Its Effectiveness on English Speaking Performance," Int. J. Emerg. Technol. Learn. IJET, vol. 14, no. 09, pp. 130-147, 2019. https://doi.org/10.3991/ijet.v14i09.10348

[44] T. Erdogan and N. Senemoglu, "PBL in teacher education: its effects on achievement and self-regulation,” High. Educ. Res. Dev., vol. 36, no. 6, pp. 1152-1165, 2017. https://doi. org/10.1080/07294360.2017.1303458 
[45] M. V. Veenman, "Assessing metacognitive skills in computerized learning environments," in International handbook of metacognition and learning technologies, Springer, 2013. https://doi.org/10.1007/978-1-4419-5546-3_11

[46] R. Azevedo and J. G. Cromley, "Does training on self-regulated learning facilitate students' learning with hypermedia?,” J. Educ. Psychol., vol. 96, no. 3, p. 523, 2004. https ://doi.org/10.1037/0022-0663.96.3.523

\section{$7 \quad$ Authors}

Mohamed Yassine Zarouk is a Ph.D. candidate in Learning Sciences and Educational Technology. Currently, he is doing his Ph.D. in Cotutelle at Faculty of Engineering of the University of Porto in Portugal, and the Faculty of Sciences of Abdelamlek Essaadi University in Morocco. The topic of his Ph.D. thesis involves the student-centered design of new technologies and environments fostering selfregulated learning in higher education. His current research interests focus on Learning Analytics and Learning Design. He holds a Master's Degree in Computer Science (Software Quality) from Abdelmalek Essaadi University. Since 2009, he has been serving as a secondary cycle teacher of Informatics at the Ministry of National Education of Morocco.

Eugénio Olivera is a Full Professor (retired), Department of Computer Science (Informatics Engineering), Faculty of Engineering, founder and Coordinator of the DAIAS- Distributed Artificial Intelligence and Agent-based Simulation Group. Responsible for the new Informatics Engineering Department start-up (2007 - March 2008). Former Coordinator of the Informatics Section of the Electrotechnical and Computing Department at FEUP, University of Porto. Co-Founder and Director (2011-2016) of LIACC- Artificial Intelligence and Computer Science Laboratory at the University of Porto (including different groups from the Faculties of Sciences and Engineering). Founder and Director (2005-2018) of PRODEI, the Doctoral Program in Informatics Engineering at FEUP.

Paula Peres gets aggregation in Online Education area, a post- $\mathrm{PhD}$, and a $\mathrm{Ph} . \mathrm{D}$. in Educational Technologies area. Master in computer science and graduate in Math Computer. She is currently teaching in the Information Systems scientific science area at ISCAP/Polytechnic of Porto. She is the coordinator of the unit of eLearning and Pedagogical Innovation of P. PORTO. She is a director of the Innovation and Digital Communication post-graduation b-learning course. She coordinates the training center at ISCAP/P.PORTO.

Mohamed Khaldi is a Full Professor at the "École Normale Supérieure" of Abdelmalek Essaadi University, and he is affiliated to the Laboratory of Informatics, Research Operational, and Statistic Applied (LIROSA) at Faculty of Sciences, Abdelmalek Essaadi University, Tétouan, Morocco.

Article submitted 2020-03-08. Resubmitted 2020-05-20. Final acceptance 2020-05-21. Final version published as submitted by the authors. 